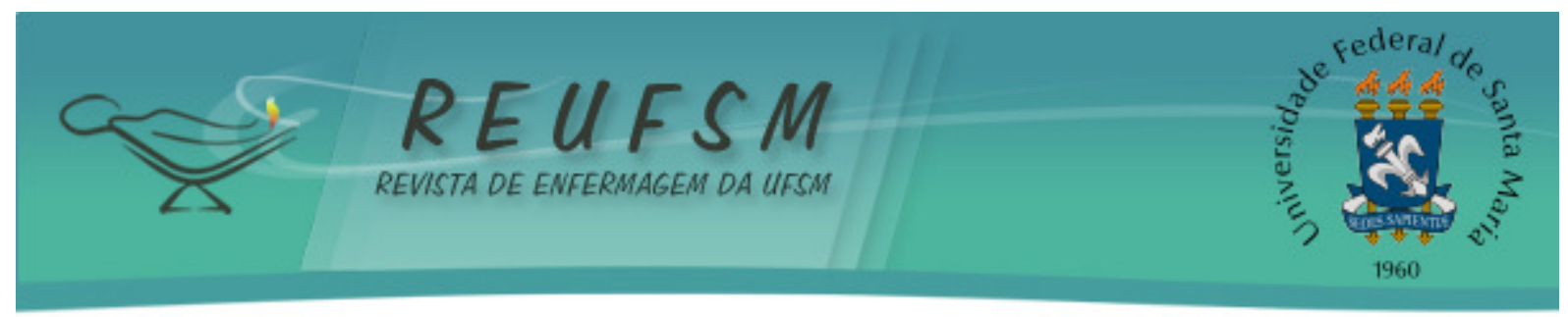

ARTIGO ORIGINAL

\title{
O PROCESSO DE INCLUSÃO DE CRIANÇAS COM NECESSIDADES ESPECIAIS DE SAÚDE NA EDUCAÇÃO INFANTIL
}

\section{THE INCLUSION PROCESS OF CHILDREN WITH SPECIAL HEALTHCARE NEEDS IN PRESCHOOL}

\section{EL PROCESO DE INCLUSIÓN DE NIÑOS CON NECESIDADES ESPECIALES DE SALUD EN LA EDUCACIÓN INFANTIL}

\author{
Aline Tatsch Neves ${ }^{1}$ \\ Daiany Saldanha da Silveira Donaduzzi ${ }^{2}$ \\ Raissa Passos dos Santos ${ }^{3}$ \\ Jaquiele Jaciara Kegler ${ }^{4}$ \\ Júlia Heinz da Silva ${ }^{5}$ \\ Eliane Tatsch Neves ${ }^{6}$
}

Doi: $10.5902 / 2179769225623$

RESUMO: Objetivo: descrever a vivência de professores da educação infantil no processo de inclusão de crianças com necessidades especiais de saúde. Método: pesquisa qualitativa desenvolvida a partir de grupo focal com dez professores de uma escola de educação infantil de um município do Rio Grande do Sul - Brasil. Os dados foram submetidos à análise de conteúdo temática. Resultados: os resultados apontaram que os professores não são preparados na sua formação para atuarem com estas crianças. E, ainda, que a rede de apoio de serviços sociais e de saúde aos profissionais e à escola é frágil ou inexistente. Conclusão: a vivência dos professores da educação infantil com as crianças com necessidades especiais de saúde acontece permeada por desafios que perpassam fragilidades em sua formação e a interação com a família dessas crianças e com os serviços de saúde.

DESCRITORES: Saúde da criança; Doença crônica; Inclusão educacional; Enfermagem pediátrica.

ABSTRACT: Aim: to describe the experience of preschool teachers in the process of inclusion of children with special healthcare needs. Method: qualitative research developed from a focal group with ten teachers from a nursery school in a municipality of Rio Grande do Sul - Brazil. The data were submitted to thematic content analysis. Results: the results pointed out that these teachers are not prepared in their training education to act with these children. Also, the social and health services support network for the professionals and to the

\footnotetext{
${ }^{1}$ Enfermeira. Especializada em Saúde Pública pela UNOPAR. Santa Maria, Rio Grande do Sul, Brasil. E-mail: alinetneves@gmail.com

${ }^{2}$ Enfermeira. Mestre em Enfermagem. Faculdade Integrada de Santa Maria. Santa Maria, Rio Grande do Sul, Brasil. E-mail: daiany.donaduzzi@ fisma.com.br

${ }^{3}$ Enfermeira. Mestre em Enfermagem. Doutoranda na McGill University. Montreal, Quebec, Canadá. E-mail: raissa.santos@mail.mcgill.ca

${ }^{4}$ Enfermeira. Especialista em Enfermagem em UTI Pediátrica e Neonatal. Mestranda em Enfermagem na Universidade Federal de Santa Maria. Santa Maria, Rio Grande do Sul, Brasil. E-mail: jake_kegler93@hotmail.com

${ }^{5}$ Enfermeira. Especialista em Saúde da Criança e do Adolescente. Mestranda em Enfermagem na Universidade Federal de Santa Maria. Santa Maria, Rio Grande do Sul, Brasil. E-mail: juheinzs@ gmail.com

${ }^{6}$ Professora Associada. Doutora em Enfermagem, Pós-doutora em Saúde Pública. Programa de Pós-graduação em Enfermagem da Universidade Federal de Santa Maria. Santa Maria, Rio Grande do Sul, Brasil. E-mail: eliane.neves@ufsm.br
} 


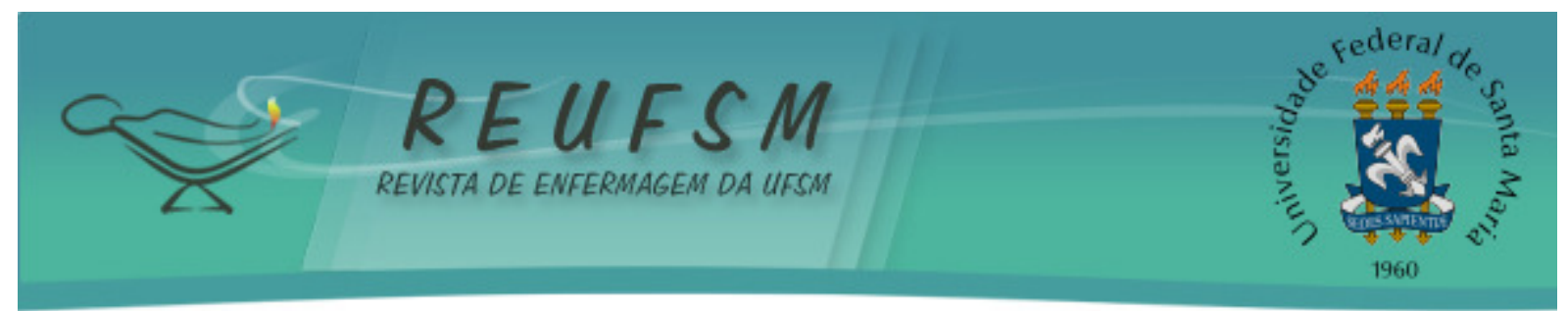

school is fragile or nonexistent. Conclusion: the experience of teachers of early childhood education with these children is permeated by challenges such as weaknesses in their professional formation and the interaction with the family and with the health services.

DESCRIPTORS: Child health; Chronic disease; Mainstreaming (education); Pediatric nursing.

RESUMEN: Objetivo: describir la experiencia de los profesores de educación infantil en el proceso de inclusión de niños con necesidades especiales de salud. Método: investigación cualitativa, desarrollada a partir de grupos focales, con diez profesores en una guardería infantil, en una ciudad en Rio Grande do Sul/Brasil. Los datos fueron sometidos a análisis de contenido temático. Resultados: los resultados evidenciaron que los profesores no tienen formación específica para trabajar con estos niños. $Y$, sin embargo, la red de apoyo a la escuela, específicamente, los servicios sociales y profesionales de la salud, son frágiles o inexistentes. Conclusión: la vivencia de los profesores de la educación infantil con estos niños ocurre basada en diversos desafios que están relacionados a fragilidades en su formación, a la interacción con la familia de los niños y con los servicios de salud.

DESCRIPTORES: Salud del niño; Enfermedad crónica; Inclusión educacional; Enfermería pediátrica.

\section{INTRODUÇÃO}

A saúde da criança passou por avanços científicos e políticos ao longo do tempo. No século XVII, a cada quatro crianças nascidas pelo menos uma morria antes de completar o primeiro ano de vida. Nesta época não existia uma assistência específica voltada a esta população e, somente a partir da fundação do primeiro hospital pediátrico em 1802 em Paris, a qualidade da assistência em pediatria começou a ser considerada. ${ }^{1}$

No Brasil, em 1984, foi criado o Programa de Assistência Integral à Saúde da Criança (PAISC), que surgiu como principal percussor de mudanças no cenário da pediatria. ${ }^{1}$ Já na década de 90, a criança e o adolescente passam a ter seus direitos regulamentados a partir da criação do Estatuto da Criança e do Adolescente (ECA) por meio da Lei 8.069/90. ${ }^{1}$

Juntamente com os avanços nas políticas públicas voltadas a esta população, as mudanças relacionadas às práticas de cuidado e os avanços tecnológicos voltados à saúde a partir da década de 1990, contribuíram para a elevação da sobrevida de crianças com doenças complexas. Neste contexto, os investimentos em serviços de alta complexidade, como a terapia intensiva neonatal e pediátrica, possibilitaram, ao mesmo tempo, aumento da expectativa de vida para essas crianças e o surgimento de um grupo de crianças clinicamente frágeis. Esse grupo foi reconhecido e denominado inicialmente nos Estados Unidos da América, em 1998, como Children with Special Healthcare Needs ${ }^{2}$ e, no Brasil, posteriormente, como crianças com necessidades especiais de saúde (CRIANES) a partir de 1999. ${ }^{3}$ 


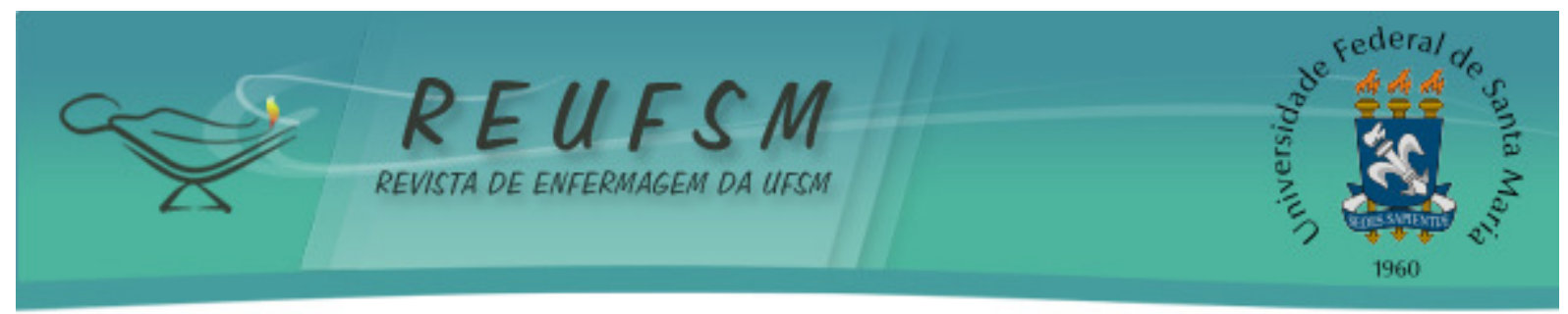

As necessidades especiais de saúde podem estar relacionadas a diversos aspectos, como por exemplo: necessidade de atendimento especializado, uso de medicamentos contínuos, nutrição especializada, dispositivo tecnológico para a saúde, necessidade educativa especial ou reabilitação por situação incapacitante tanto física, auditiva, intelectual, mental ou múltipla. ${ }^{4}$

Em se tratando da inclusão destas crianças na escola, estudo desenvolvido em 2012 na Bahia destacou que faltam aos professores embasamento teórico e apoio necessários para atuar em sala de aula com este público. ${ }^{5}$ Este estudo propõe abordar a inclusão destas crianças nas escolas, na perspectiva de contribuir com sua qualidade de vida e sua integração à sociedade.

Neste cenário, em 2015, foi instituída a Lei Brasileira de Inclusão da Pessoa com Deficiência (lei $n^{\circ}$ 13.146), que estabelece um novo conceito de integração total, garantindo direito à igualdade de oportunidades com as demais pessoas ao tratar de questões relacionadas à acessibilidade, educação e trabalho e ao combate ao preconceito e à discriminação. ${ }^{6}$

Dessa forma, este estudo justifica-se por abordar um tema relevante, com uma população emergente e que em termos de cenário de pesquisa, um trabalho de revisão realizado em 2010 sobre as CRIANES, identificou o hospital como o local mais frequente nas pesquisas com este grupo de crianças, enquanto a escola não apareceu. ${ }^{7}$

Frente ao exposto, questionou-se: como ocorre o processo de inclusão de CRIANES em escolas de educação infantil na perspectiva dos profissionais de educação? Tem como o objetivo de descrever a vivência de professores da educação infantil no processo de inclusão de crianças com necessidades especiais de saúde.

\section{MÉTODO}

Trata-se de um estudo descritivo, exploratório com abordagem qualitativa, desenvolvido com professores de uma escola de educação infantil de um município do Estado do Rio Grande do Sul - Brasil.

A população do estudo constituiu-se de 11 professores que atuavam na escola nos turnos manhã e tarde. Após a aplicação dos critérios de seleção, quais sejam: atuar há pelo menos um ano como professor da educação infantil e pertencer ao quadro de servidores do município, totalizaram 10 participantes, sendo um excluído por atuar há menos de um ano na escola. Não houve nenhuma recusa. 


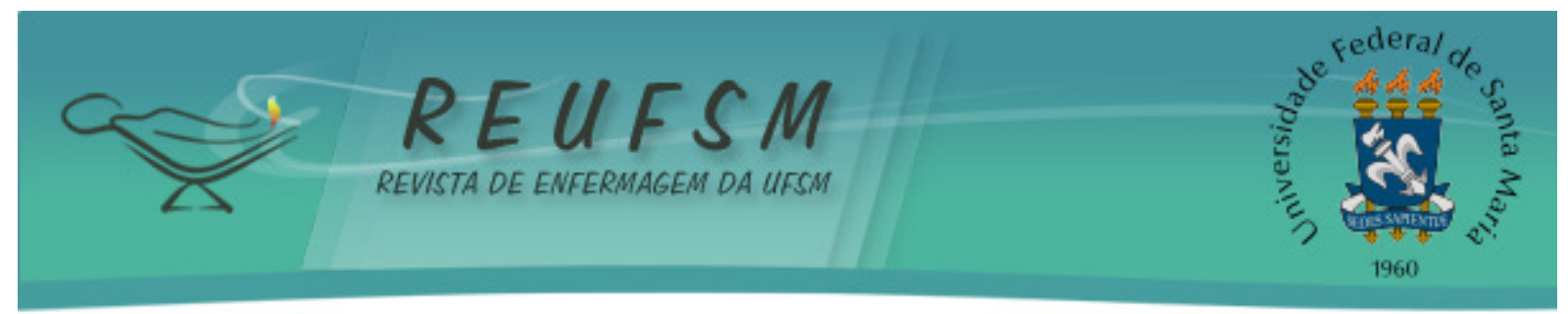

A coleta de dados ocorreu no mês de julho de 2014, por meio da técnica de Grupo Focal (GF), considerando que esta pode ofertar possibilidades que extrapolam a condição de apenas coletar dados, viabilizando discussões e elaboração de estratégias para solucionar problemas e transformar realidades, através da aprendizagem coletiva e troca de experiências sobre o tema abordado. Os participantes aprendem, dialogam e participam da construção dos resultados da pesquisa. ${ }^{8}$ A equipe de coordenação do GF constituiu-se por dois observadores participantes que foram capacitados, previamente, em relação à aplicação da técnica a fim de qualificar o desenvolvimento da coleta de dados.

O GF realizado com os professores teve uma duração de duas horas. Após a transcrição dos dados e uma análise preliminar, concluiu-se que o grupo realizado foi satisfatório, ou seja, havia densidade suficiente de estruturas de significados capazes de responder ao objetivo da pesquisa, encerrando-se, portanto, a etapa de coleta de dados.

O GF foi gravado, com o conhecimento e autorização dos participantes e, posteriormente, o áudio transcrito. O material impresso constitui-se no corpus da pesquisa, que foi submetido à análise de conteúdo temática, ${ }^{9}$ seguindo as etapas de pré-análise, exploração do material e tratamento dos resultados.

$\mathrm{Na}$ pré-análise, realizou-se a organização de todo o material coletado no GP e posterior, foi feita a leitura flutuante, buscando identificar as primeiras unidades de registro. A etapa de exploração do material foi sistematizada aplicando-se uma codificação cromática para identificação das unidades de registro, que foram agrupadas por afinidade temática para a constituição das categorias. No tratamento dos resultados, os achados foram interpretados e discutidos com a literatura científica pertinente à temática.

A fim de preservar o anonimato, os participantes foram identificados com codinome de pedras preciosas. Os preceitos éticos foram assegurados de acordo com a Resolução 466/12, do Conselho Nacional de Saúde. Todos os participantes assinaram o Termo de Consentimento Livre e Esclarecido. O estudo foi aprovado pelo Comitê de Ética em Pesquisa da Universidade Federal de Santa Maria em 25/06/2014, sob o número do CAAE: 31061114.5.0000.5346. 


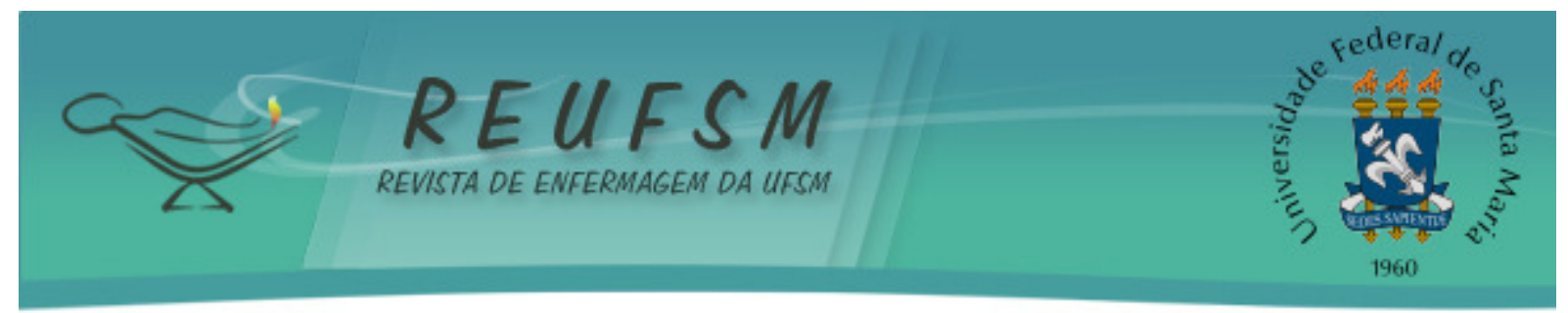

\section{RESULTADOS E DISCUSSÃO}

Os participantes do estudo foram todas do sexo feminino, com idades entre 29 e 59 anos, com média de 44 anos. O tempo de formação variou de 08 a 28 anos e o de atuação na escola de 02 a 09 anos. Após a análise dos dados, os resultados do estudo foram agrupados em categorias:

\section{A formação dos professores não prepara para atuar com crianças com necessidades especiais de saúde}

A necessidade de capacitação (preparo) para atuar com CRIANES evidenciou-se nos enunciados dos participantes como uma lacuna na formação acadêmica e profissional, visto que este tema não foi trabalhado durante a graduação. No enunciado a seguir, pode ser observada a necessidade de qualificação para esta prática:

[...] não foi fácil para nós, os nossos primeiros [alunos com necessidades especiais de saúde] entendeu? Então, eu acredito que não fui preparada na universidade, quando fiz pedagogia, para trabalhar com crianças especiais. Acredito que aqui ninguém foi. Então existe um grande problema, sabe? Da universidade, do curso de pedagogia não preparar o seu aluno para enfrentar algum problema especial. (Ágata)

Assim, percebe-se que existe falta de preparo para trabalhar com estas crianças e isto ocorre desde a formação, na qual os professores não foram preparados para trabalharem com CRIANES. O aumento de CRIANES demanda educadores preparados e responsivos às suas necessidades. Estudo desenvolvido em 2012 na Bahia com o objetivo de descrever a percepção de professores e psicólogos sobre a inclusão de crianças com necessidades especiais na escola já havia identificado resultado semelhante quanto ao despreparo técnico e teórico dos professores para atuar com estas crianças. ${ }^{5}$

É necessário que os profissionais saibam identificar as demandas desta população e, a partir disto, consigam formular estratégias para o atendimento das necessidades especiais de saúde e educacionais, contar com o apoio de serviços suplementares para auxílio na prática profissional, além de conhecer e realizar um trabalho pautado na legislação, assegurando os direitos destas crianças. ${ }^{10}$

Os enunciados a seguir descrevem as consequências da falta de preparo no cotidiano da prática pedagógica: 


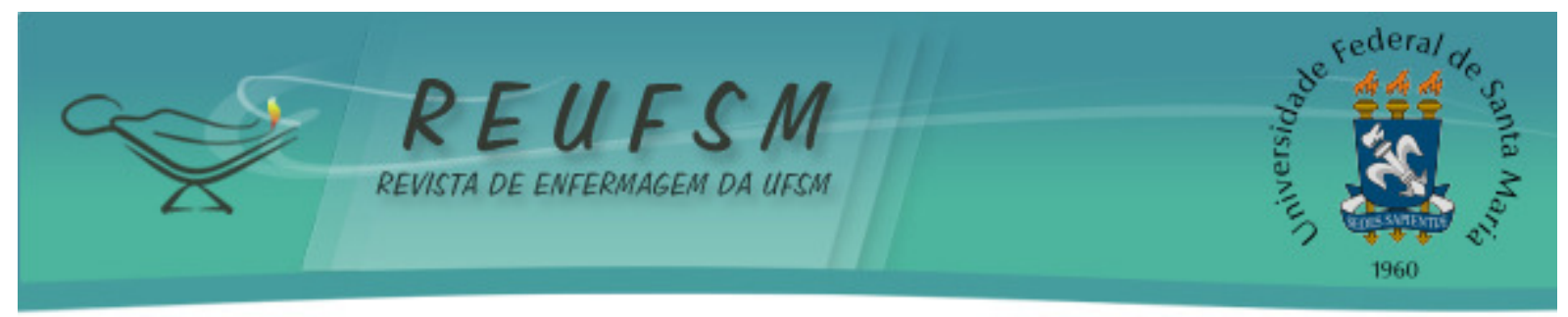

[...] a gente já agiu, muitas vezes, por intuição. (Hematita)

[...] de repente já tenha até errado com uma criança por eu não ter conhecimento, entendeu? (Ágata)

É possível perceber que a falta de preparo faz com que os professores, muitas vezes, não saibam como agir frente às demandas das CRIANES e sintam-se aflitos por isto. A educação continuada e permanente é essencial para que estes profissionais vivenciem as adaptações curriculares que estão em constante transformação e possam aplicá-las, além de possibilitar à superação de possíveis deficiências oriundas da formação no que se refere ao atendimento das singularidades das CRIANES. ${ }^{11}$

O preparo do professor acaba acontecendo no dia a dia, por meio da vivência e da realidade que cada criança traz, buscando conhecimento e o melhor entendimento delas, conforme apontam os enunciados:

[...] a gente recebe a criança primeiro e depois a gente vê o que a gente vai poder fazer [...]. (Ágata)

[...] em primeiro lugar a gente já tem um educador especial que nos dá apoio e em segundo lugar nós saímos à procura. A gente vai procurar entendeu? [conhecimento]. (Cristal)

Os enunciados destacam que apesar dos professores não saberem como agir, eles buscam alternativas para que ocorra a aceitação da CRIANES no espaço escolar. Estudo de revisão desenvolvido em teses e dissertações, em 2015, sobre a inclusão de crianças com autismo, apontou que os professores desconhecem a patologia e sentem-se despreparados para atuar com esta população. ${ }^{12}$

Os educadores precisam de uma formação que possibilite instigar sua criatividade para o desenvolvimento de um trabalho diversificado e integrado em sala de aula. Dessa forma, podem estimular trocas entre os alunos, apesar das suas diferenças e singularidades, para que saibam utilizar metodologias alternativas de ensino para abranger todos os públicos e para que estejam preparados para as adaptações curriculares e condições materiais concretas cada vez mais modernas. ${ }^{13}$

Dessa forma, a inclusão de CRIANES na escola regular é um desafio a ser enfrentado por todos que estão envolvidos neste processo, mas que é algo cada vez mais comum, como pode observado nos enunciados a seguir:

[...] é uma característica da nossa escola essa aceitação [da criança]. (Hematita) 


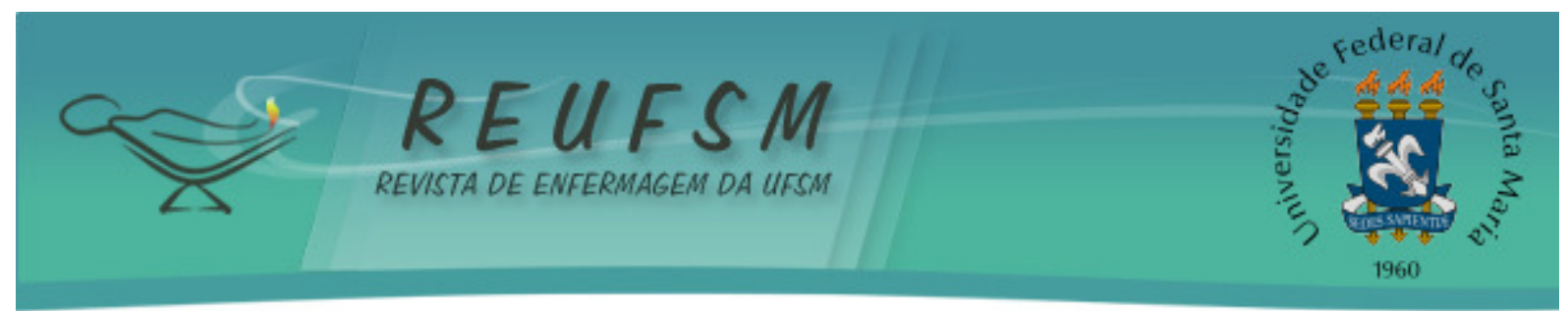

[...] nossa escola é referência de todas as escolas municipais em educação infantil, a nossa escola é a que tem mais crianças [com necessidades especiais se saúde]. (Ágata)

É possível perceber que ocorre a inclusão/aceitação das CRIANES no espaço escolar e que estas fazem parte da rotina da escola. Já o preparo dos professores para trabalhar nesse cotidiano é construído através da prática vivenciada em sala de aula, como se apresenta no enunciado a seguir:

[...] tu acabas meio que tendo que fazer uma pesquisa sobre aquele caso específico para ver o que tu podes ajudar e o que tu vais limitar e como vais lidar com os colegas, porque é uma coisa que envolve a turma toda [...]. (Quartzo)

A prática constrói um conhecimento que, muitas vezes, é específico para aquela criança e a demanda de cuidado que ela necessita. Os professores sabem que quanto mais conhecerem seus educandos, maiores condições terão de se prepararem emocional e pedagogicamente para o desafio da inclusão escolar. Eles reconhecem a necessidade de estarem se capacitando para promover uma educação de qualidade para as crianças que possuem necessidades especiais. ${ }^{14}$

A cada nova criança que a escola acolhe a busca por conhecimento é novamente vivenciada, e realizada pelos professores, no intuito de considerar a singularidade desta, como emergiu no enunciado de Quartzo:

[...] minha experiência com essas crianças é de buscar o conhecimento do que eu posso colaborar em sala de aula. Eu busco leituras, converso com a mãe [...]. (Quartzo)

A fala demonstra que a inclusão ocorre por meio da busca de conhecimento por parte dos professores, o que influencia na prática pedagógica e no cotidiano de trabalho, fazendo com que as turmas e os professores se adaptem a esta realidade.

O trabalho com a CRIANES precisa ser individualizado, o que demanda tempo e apoio de outros profissionais, conforme demonstrado no enunciado a seguir:

[...] uma turma com 23 alunos de maternal, eu preciso que fiquem de duas a três meninas na sala para que eu, como pedagoga, possa dar essa atenção para ele [CRIANES]. [...] trabalho só com ele a alimentação para poder dar o resultado, o objetivo que eu quero alcançar. Porque tu tens objetivos, e com a inclusão são objetivos específicos que tu tens que desenvolver [...]. (Jade) 


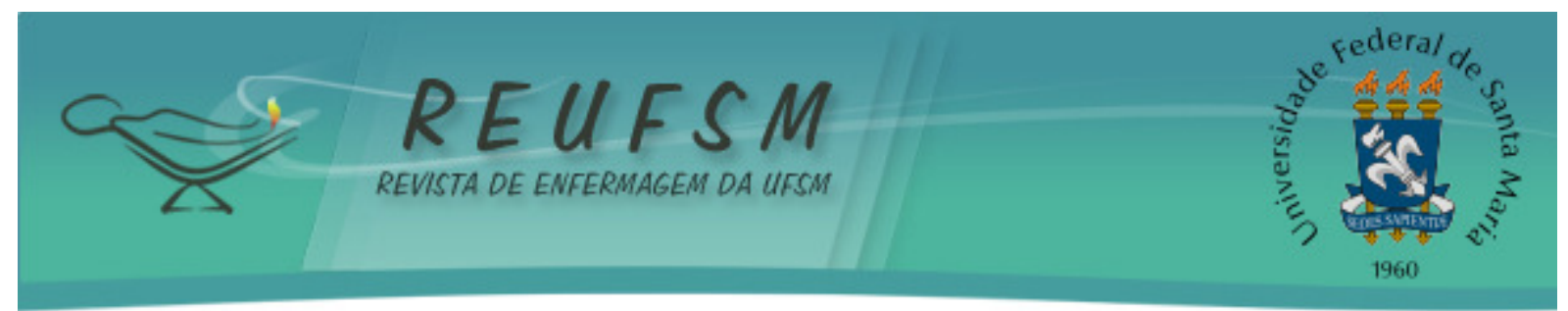

Percebe-se que os professores trabalham de modo a dar o apoio necessário para que a inclusão ocorra da melhor forma possível, por mais que não tenham todos os subsídios necessários e o apoio efetivo de outros profissionais. Em um estudo que avaliou como ocorria a inclusão escolar, verificou-se que há necessidade do acompanhamento ao professor, do apoio especializado, conforme o previsto na política educacional, contudo, isto não tem sido uma prática recorrente. ${ }^{14}$

A inclusão requer a reformulação de objetivos e metas a serem alcançadas pelos alunos, o que significa que o professor deve adaptar à realidade da turma e, ao mesmo tempo, fazer com que a inclusão não prejudique o andamento normal das atividades. Nesse sentido, apresentam-se os enunciados:

[...] a gente tem que ser bem flexível quanto aos nossos planejamentos e aos nossos objetivos. Então aqueles objetivos que eu julgava serem os necessários e os importantes para o nível do maternal I eu já tive que mudar totalmente e adaptar à realidade da turma [...] a gente replaneja os objetivos, reelabora tudo para tentar sair da melhor forma possível e atender o mínimo do mínimo do necessário dos objetivos para aquela faixa etária. (Ametista)

Dependendo do perfil da turma é que a gente vai adaptando e [re] pensando as estratégias. (Cristal)

A inclusão faz com que os professores repensem suas estratégias diariamente, prevalecendo aquela que melhor se adapta a realidade da turma como um todo. Isto proporciona que não somente a CRIANES se beneficie do aprendizado, mas transforma o processo educacional em uma prática de inclusão e aprendizado. Em pesquisa realizada em escolas de São Paulo em 2012 sobre a inclusão de crianças com deficiência, os professores relataram a necessidade de formação continuada e apoio institucional para atuar no processo de inclusão destas crianças. ${ }^{15}$

A inclusão de CRIANES na escola regular subentende um currículo ajustado, constantemente e progressivamente, recursos educativos adaptados, tecnologia assistida e avaliações de desempenho diferenciadas, para dar uma resposta adequada às necessidades educacionais destes alunos, possibilitando, desta forma, a igualdade de oportunidades para a construção do conhecimento. ${ }^{11}$ 


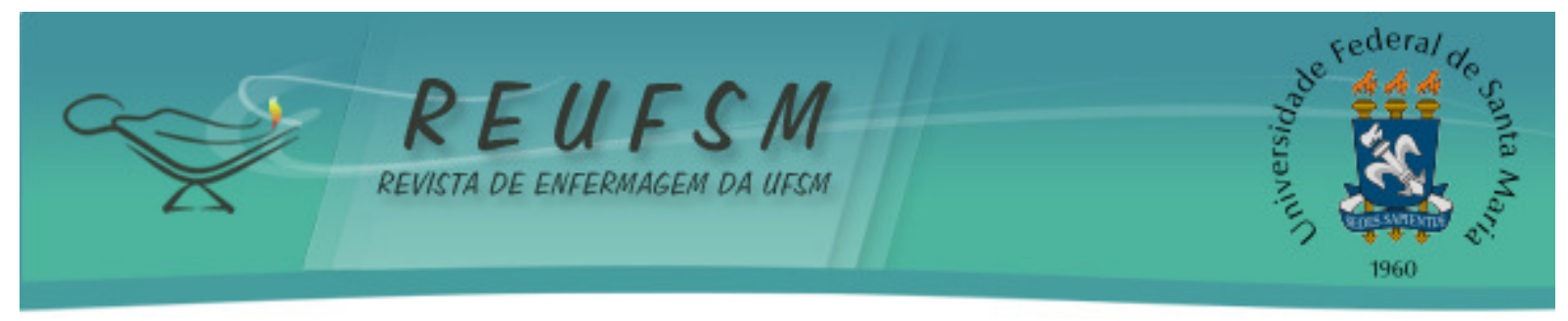

A configuração das redes de apoio de professores na educação infantil no contexto das crianças com necessidades especiais de saúde

As redes de apoio se fazem necessárias para que a criança seja amparada em todas as esferas da sociedade, de forma que seja incluída de modo efetivo. A escola e a família fazem parte dessa rede de apoio e, no momento em que a CRIANES é inserida no ambiente escolar, essa parceria entre escola e família deve ser fortalecida, conforme aponta o enunciado a seguir:

\section{[...] quando a família te apoia e você consegue chegar a um consenso,} a coisa começa a funcionar. (Quartzo)

Assim, percebe-se como é importante que a família esteja sempre presente no cotidiano da escola, apoiando a criança e o professor no desenvolvimento das atividades escolares. A família faz parte das redes sociais, que são estruturas coletivas, capazes de tornar seus sujeitos autônomos, empoderados, reflexivos e solidários em suas ações e relações, conscientes de suas atitudes, através do apoio contínuo. ${ }^{16}$

Em estudo realizado com os professores, evidenciou-se que não há planejamento ou avaliação conjunta entre professores e família e, que esta falta de diálogo pode ser responsável pelas divergências no modo de intervirem junto a alunos com necessidades especiais. Por outro lado, os professores reconhecem a necessidade de construírem relações colaborativas com os pais, para que as representações negativas das CRIANES sejam superadas. ${ }^{13}$

Pode-se perceber que, quando há interação efetiva entre a família e o professor, a prática pedagógica com a criança no ambiente escolar tende a ter um melhor funcionamento. Isto pode facilitar o aprendizado e a inclusão das CRIANES, considerando que há estudantes que permanecem isolados em classe, outros que interagem apenas com a cuidadora e ainda, os que vivenciam situações de superproteção e infantilização em decorrência da condição de saúde. ${ }^{13}$

O diálogo entre a escola e a família facilita a aproximação dos pais e professores, como demonstram os enunciados:

[...] o diálogo com esses pais é mais constante, é bem aberto. (Cristal) [...] eu acho que a gente costuma ter mais contato com esses pais. (Citrine)

Mediante a aproximação entre família e escola, o professor deve ter sensibilidade para conversar com estes pais devido à fragilidade que estes, muitas vezes, se encontram, a fim de 


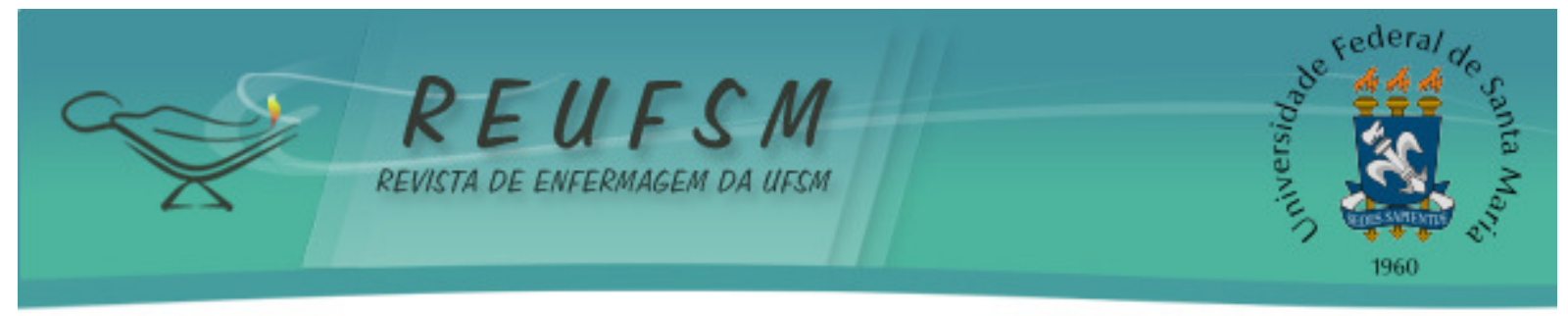

não comprometer o processo de inclusão da CRIANES no ambiente escolar, como aparece no enunciado de Ônix:

[...] tem que comer pelas beiradas, eu digo, porque qualquer palavra atinge, uma palavra mal dita ofende. Outra palavra distancia, tiram da escola. Tem que comer pelas beiradas! (Ônix)

A família torna-se essencial para o andamento da prática pedagógica, pois o professor precisa deste apoio para que o trabalho da escola tenha continuidade em casa. Para isto, a família precisa ser acolhida e adquirir confiança nos professores. Essa preocupação é encontrada nos enunciados dos participantes:

[...] eu vejo que a gente tem meio que objetivos com as famílias quando tu queres atingir a criança [...]. (Ágata)

[...] muito do nosso trabalho pedagógico precisa da continuidade em casa [...] existe essa conversa para que a coisa não seja só na sala de aula que eu consiga levar para casa. (Jade)

[...] a gente acaba meio que acolhendo aquela mãe mostrando para ela que ela pode confiar em mim. (Quartzo)

O ambiente escolar deve estabelecer um vínculo com a família, para que esta tenha condições de dar continuidade em casa às atividades desenvolvidas pelos professores. A família desempenha um importante papel no que refere ao processo de inclusão da CRIANES no ambiente escolar, por meio das informações transmitidas aos professores acerca do desenvolvimento da criança em casa, bem como incentivando e continuando com o processo de aprendizagem iniciado na escola. ${ }^{17}$

Estudo de revisão desenvolvido em 2012 apontou lacunas nas produções científicas de estudos que abordem a família no processo de inclusão das CRIANES na escola. Também ressalta a importância da relação família-escola para que o processo de inclusão seja bem sucedido. ${ }^{18}$

Outro componente importante dessa rede são os serviços de saúde, que deveriam formar parcerias com as escolas, devido estas possuírem em sua rotina CRIANES. Os enunciados a seguir denotam a relação entre a escola e os serviços de saúde:

[...] ninguém nos apoia só nós mesmos, a gente enfrenta dificuldades porque eu consegui ficar dois anos na escola tentando encaminhar uma menina para a fono[audiologia] e ela saiu daqui sem a fono[audiologia] o sistema não tem essa parceria, o sistema municipal eu digo. (Quartzo) 


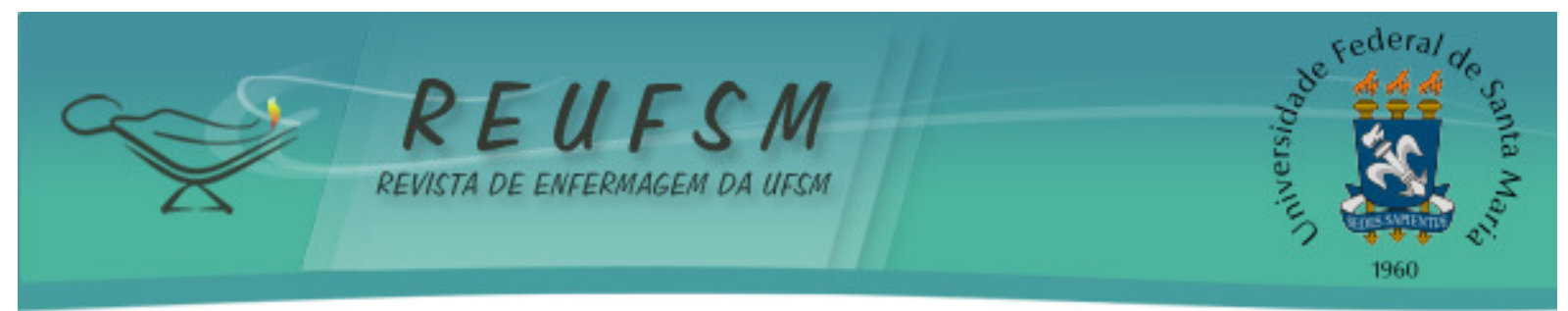

[...] nós temos um posto de saúde aqui dentro da escola, perguntas no que eles nos auxiliam? Em nada. (Ônix)

Apesar de as CRIANES necessitarem de serviços sociais e de saúde para além das outras crianças, o que se percebe na fala dos participantes, é a fragilidade de acesso destas crianças aos serviços de saúde. Dessa forma, com o aumento desta população torna-se necessária a reorganização dos serviços existentes bem como a implantação de novos serviços, buscando a integração e cooperação mútua destes, a fim de proporcionar uma melhoria na qualidade da assistência prestada a estas crianças. ${ }^{19}$

A falta de amparo do sistema de saúde às escolas constitui-se de uma lacuna na atenção a essas crianças, pois é na escola que se encontra o foco da educação permanente e continuada. Estudo realizado com o objetivo de descrever a rede social de cuidados de uma CRIANES no contexto da comunidade demonstrou a fragilidade da rede de serviços de saúde a estas crianças. E ainda, que em virtude das dificuldades de acesso e da baixa resolutividade dos serviços de atenção primária à saúde, as famílias acabam buscando atendimento para as CRIANES nos serviços de maior complexidade. ${ }^{20}$

Assim, destaca-se a importância do enfermeiro no cuidado às CRIANES e suas famílias, no sentido de buscar a identificação das fontes de apoio sociais na comunidade, promovendo uma assistência articulada e integral para o atendimento das necessidades desta população. ${ }^{19}$

Ainda, o enfermeiro precisa conhecer as condições socioeconômicas e culturais da família da CRIANES, a fim de implementar um cuidado que atenta às reais necessidades do núcleo familiar, com vistas à promoção da saúde e inclusão social da criança e de sua família na comunidade. ${ }^{21}$

\section{CONCLUSÃO}

A vivência dos professores da educação infantil com as CRIANES acontece permeada por desafios que perpassam fragilidades em sua formação e na interação com a família dessas crianças e com os serviços de saúde.

As CRIANES estão sendo inseridas no ambiente escolar lentamente e de forma gradual, porém enfrentam a falta de preparo dos professores para trabalhar com estas crianças, visto que este é um grupo relativamente novo, que está emergindo para a realidade escolar e que, muitas vezes, não está preparada para isso. 


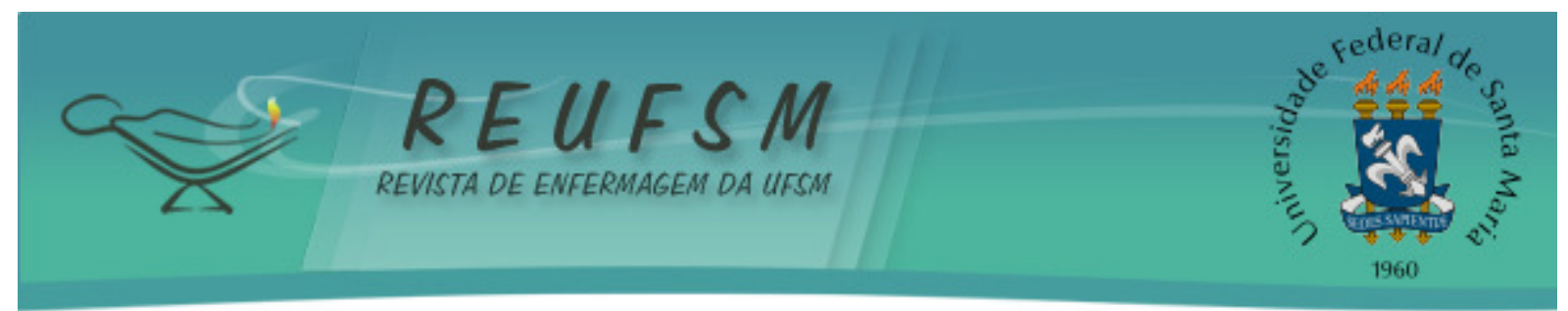

Os resultados apontaram, ainda, para a existência de fragilidades na interação entre a família, os serviços de saúde e a escola. Os professores tentam aproximar-se mais da família, acolhendo-a, no entanto, isto nem sempre é efetivo. Os serviços de saúde desconhecem, na maioria das vezes, a presença dessas crianças nas escolas de educação infantil e, consequentemente, tem sua atuação diminuída neste contexto.

As implicações deste estudo para a prática de enfermagem referem-se à necessidade do desenvolvimento de educação em saúde nas escolas, visto que este é um campo rico e possui carência de ações que visem o bem-estar dos estudantes.

As proposições deste estudo dizem respeito à necessidade de construção de políticas públicas específicas para esta clientela, com o objetivo de proporcionar uma melhor qualidade de vida para estas crianças e de trabalho para os professores.

Como limitação do estudo, aponta-se a impossibilidade de generalizações dos resultados por se tratar de uma realidade específica de um município do Estado do Rio Grande do Sul/Brasil. Para tanto, se faz necessária a realização de outros estudos que contemplem esta temática afim de que os resultados possam ser confrontados, rediscutidos e ampliados, dada a importância do tema.

\section{REFERÊNCIAS}

1. Araújo JP, Silva RMM, Collet N, Neves ET, Toso BRGO, Viera CS. História da saúde da criança: conquistas, políticas e perspectivas. Rev bras enferm. [Internet] 2014 nov-dez [acesso em 2016 nov 24]; 67(6):1000-7. Disponível em: http://www.scielo.br/pdf/reben/v67n6/00347167-reben-67-06-1000.pdf

2. McPherson M, Arango P, Fox H, Lauver C, McManus M, Newacheck PW, et al. A new definition of children with special health care needs. Pediatrics. 1998 Jul; 102(1):137-41.

3. Merck T, MCelfresh P. Cuidados à criança centrados na família durante a doença e hospitalização. In: Honckenberry MJ, Wilson D. Wong Fundamentos de Enfermagem Pediátrica. $9^{\mathrm{a}}$ ed. Rio de Janeiro: Elsevier; 2014. p. 588-609.

4. Flores JC, Carrillo D, Karzulovic L, Cerda J, Araya G, Matus MS, et al. Niños y adolescentes com necesidades especiales de atención em salud: prevalência hospitalaria y riesgos asociados. Rev méd Chile. [Internet] 2012 [cited 2016 Nov 24]; 140(4): 458-65. Available from: http://www.scielo.cl/scielo.php?script=sci_arttext\&pid=S003498872012000400006\&lng=es\&nrm=iso

5. Braz-Aquino FS, Ferreira IRL, Cavalcante LA. Concepções e ações de psicólogos e docentes sobre a inclusão. Psicol ciênc prof. [Internet] 2016 abr-jun [acesso em 2017 fev 22]; 36(2): 255-66. Disponível em: http://www.scielo.br/pdf/pcp/v36n2/1982-3703-pcp-36-20255.pdf 


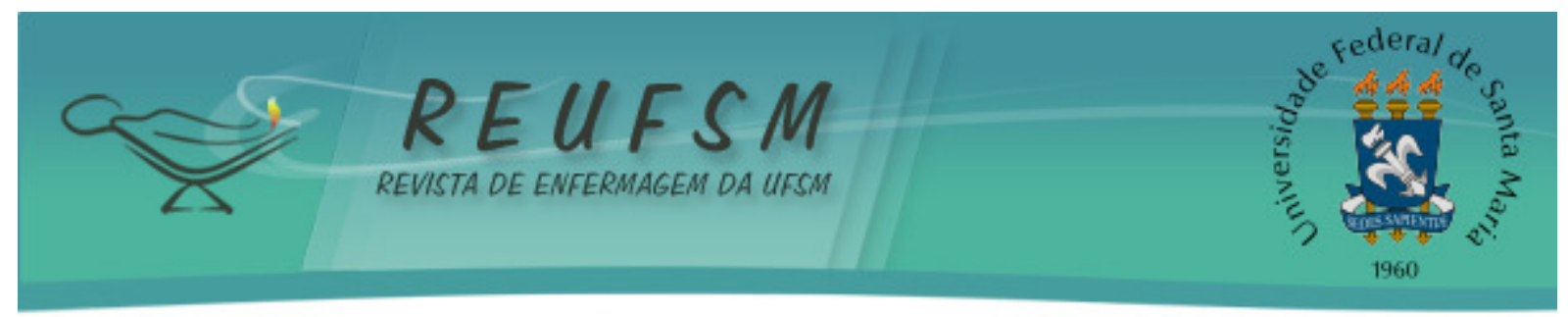

6. Brasil. Lei n. 13.146, de 6 de julho de 2015. Institui a Lei Brasileira de Inclusão da Pessoa com Deficiência (Estatuto da Pessoa com Deficiência). Diário Oficial da União, Brasília, 7 jul. 2015. Seção 1, p. 2.

7. Silveira A, Neves ET. Crianças com necessidades especiais de saúde: tendências das pesquisas em enfermagem. Rev enferm UFSM. [Internet] 2011 [acesso em 2017 fev 22];1(2):254-60. Disponível em: http://cascavel.ufsm.br/revistas/ojs2.2.2/index.php/reufsm/article/view/2500/1637

8. Dall'agnol CM, Magalhães AMM, Mano GCM, Olschowsky A, Silva FP. A noção de tarefa nos grupos focais. Rev gaúch enferm. [Internet] 2012 mar [acesso em 2016 nov 24]; 33(1): 186-90. Disponível em: http://www.scielo.br/scielo.php?script=sci_arttext\&pid=S198314472012000100024

9. Bardin L. Análise de conteúdo. Lisboa: Edições 70; 2011.

10. Braga TMS, Bomfim DP, Sabbag Filho D. Necessidades especiais de escolares com Diabetes Mellitus Tipo 1 identificadas por familiares. Rev bras educ espec. [Internet] 2012 jul-set [acesso em 2016 nov 28]; 18(3):431-48. Disponível em: http://www.scielo.br/pdf/rbee/v18n3/a06.pdf

11. Antunes HS, Rech AJD, Ávila CC. Educação inclusiva e formação de professores: desafios e perspectivas a partir do Pacto Nacional pela Alfabetização na Idade Certa. Práxis Educativa. [Internet] 2016 jan-abr [acesso em $2016 \mathrm{dez} 08$ ]; 11(1):171-98. Disponível em: http://www.revistas2.uepg.br/index.php/praxiseducativa/article/view/8162/4762

12. Schmidt C, Nunes DRP, Pereira DM, Oliveira VF, Nuernberg AH, Kubaski C. Inclusão escolar e autismo: uma análise da percepção docente e práticas pedagógicas. Psicol teor prát. [Internet] 2016 jan-abr [acesso em 2017 fev 22]; 18(1):222-35. Disponível em: http://pepsic.bvsalud.org/scielo.php?script=sci_arttext\&pid=S1516-36872016000100017

13. Matos SN, Mendes EG. Demandas de professores decorrentes da inclusão escolar. Rev bras educ espec. [Internet] 2015 jan-mar [acesso em 2016 nov 28]; 21(1): 9-22. Disponível em: http://www.scielo.br/pdf/rbee/v21n1/1413-6538-rbee-21-01-00009.pdf

14. Neres CC, Kassar MCM. Inclusão escolar de crianças com deficiência: do direito à matrícula ao acesso ao conhecimento em trajetórias escolares. International Studies on Law and Education. [Internet] 2016 jan-abr [acesso em 2016 nov 28]; 22:39-50. Disponível em: http://www.hottopos.com/isle22/39-50CeliMonica.pdf

15. Briant MEP, Oliver FC. Inclusão de crianças com deficiência na escola regular numa região do município de São Paulo: conhecendo estratégias e ações. Rev bras educ espec. [Internet] 2012 jan-mar [acesso em 2017 fev 22]; 18(1):141-54. Disponível em: http://www.scielo.br/scielo.php?script=sci_arttext\&pid=S1413-65382012000100010

16. Moraes JRMM, Cabral IE. The social network of children with special healthcare needs in the (in)visibility of nursing care. Rev latinoam enferm. [Internet] 2012 Mar-Apr [acesso em 2016 dez 08]; 20(2):282-8. Disponível em: http://www.scielo.br/pdf/rlae/v20n2/10.pdf

17. Christovam ACC, Cia F. O envolvimento parental na visão de pais e professores de alunos com necessidades educacionais especiais. Rev bras educ espec. [Internet] 2013 out-dez 


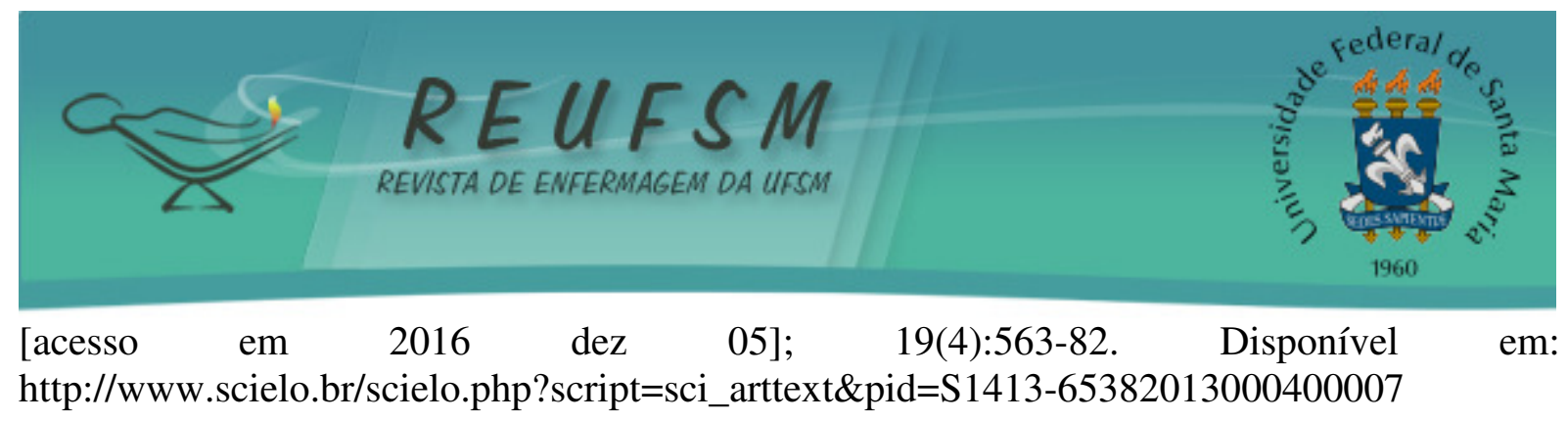

18. Maturana APPM, Cia F. Educação especial e a relação família - escola: análise da produção científica de teses e dissertações. Psicol Esc Educ. [Internet] 2015 maio-ago [acesso em 2017 fev 22]; 19(2):349-58. Disponível em: http://www.scielo.br/scielo.php?script=sci_arttext\&pid=S1413-85572015000200349

19. Astolpho MP, Okido ACC, Lima RAG. Rede de cuidados a crianças com necessidades especiais de saúde. Rev bras enferm. [Internet] 2014 mar-abr [acesso em 2016 nov 24]; 67(2): 213-9. Disponível em: http://www.redalyc.org/articulo.oa?id=267030687007

20. Neves ET, Andres B, Silveira A, Arrué AM. A rede social de cuidados de uma criança com necessidade especial de saúde. Rev eletrônica enferm. [Internet] 2013 abr-jun [acesso em 2016 dez 08]; 15(2):533-40. Disponível em: https://www.fen.ufg.br/fen_revista/v15/n2/pdf/v15n2a28.pdf

21. Neves ET, Cabral IE, Silveira A. Rede familial de crianças com necessidades especiais de saúde: implicações para a enfermagem. Rev latinoam enferm. [Internet] 2013 mar-abr [acesso em 2017 jun 20]; 21(2):562-70. Disponível em: http://www.scielo.br/pdf/rlae/v21n2/pt_01041169-rlae-21-02-0562.pdf

Data de submissão: 16/01/2017

Data de aceite: $25 / 08 / 2017$

Autor correspondente: Aline Tatsch Neves

Email: alinetneves@gmail.com

Endereço: Rua: Pedro Santini, 3497 Casa: 69 Fase: C Bairro: Nossa Senhora de Lourdes. CEP: $97060-480$ 